\title{
TRAUMATIC ANEURYSM OF THE LEFT VENTRICLE
}

\author{
BY \\ P. T. O'FARRELL \\ From St. Vincent's Hospital, Dublin \\ Received December 4, 1938
}

\begin{abstract}
Although aneurysm of the heart is still thought to be a somewhat rare and unusual pathological condition, recent work shows that it occurs not infrequently after coronary occlusion and infarction. Parkinson, Bedford, and Thompson (1938) estimate that it occurs in 9 per cent. of cases of cardiac infarction examined at necropsy. In the absence of coronary disease, aneurysm of the heart appears to be exceedingly rare ; and trauma as an exciting cause is seldom referred to in papers on the subject. Warburg (1938) in a recent monograph has collected, from papers and reports dating back to the year 1676, 197 cases of cardiac lesions due to non-penetrating injuries, but of these only two or three appear to be instances of traumatic aneurysm of the heart.

The case recorded here is one of traumatic aneurysm of the left ventricle, due to a non-penetrating injury to the thorax. Although the diagnosis was not made during life, the case presents some interesting points clinically and medico-legally.
\end{abstract}

He was a man, aged 59 years, a non-smoker and life abstainer. While driving a motor car he was involved in a head-on collision with another car on July 12,1936 . Immediately after the accident he noticed pain in his knees only. He was able to help some other people who had been injured, and later with assistance he changed the wheel of his car. Following this he experienced sudden severe pain in the region of his heart and became short of breath. An injection of morphia was given, and as a condition of shock still continued, he was taken by car to a neighbouring town. On arrival there he was seen by a doctor, and next day was admitted to the local hospital, as the præcordial pain had again become severe and was accompanied by marked dyspnœa. A tentative diagnosis of pericarditis was made. While in hospital he developed a left-sided pleurisy, and an X-ray photograph is said to have revealed a fracture of one of the left lower ribs near the vertebral junction. He was discharged from hospital on July 23 and returned to his own home by train.

On July 30 he was seen by a surgeon, who reported as follows : "There were tender points over the left costal cartilages and over the xiphisternum, and 
over the eleventh rib at the back. The patient showed abnormal nervousness and increased reflexes. He breathed with short gasps and could not take a deep breath ; his pulse rate was 98 . In my opinion the patient has suffered a crushing injury to the chest, probably due to striking against the steering wheel at the moment of collision. The crush has injured the costo-condral and costo-sternal junctions over the fifth to seventh ribs, which interfere with normal breathing. He will be confined to his house for at least a month, but may be able to do some light work in three months' time. His expectation of life has been adversely affected."

On August 6 he was seen by the present writer on account of an acute heart attack on the previous evening. On examination he was in great distress from severe shortness of breath, with a feeling of constriction and pain in the chest. The heart was rapid and irregular (auricular fibrillation). The blood pressure was slightly raised and there was distinct præcordial tenderness. On careful inquiry there was no history of any significant illness previous to the accident and nothing to suggest that there ever had been any symptoms of cardiac disability. With complete rest, sedatives, and digitalis the cardiac condition seemed to undergo improvement. As the heart rate became steadier the sounds became of a " tic tac" quality, and the breathing, though less embarrassed, always seemed to occur in short, sharp "whiffs." From time to time he experienced attacks of pain like angina of varying severity, and morphia had to be given on several occasions. Throughout his illness he was nervous and apprehensive, and there was always some slight tenderness over the præcordium.

At the end of August he was allowed up for a short time, but as this caused respiratory distress he was ordered back to bed. After a further period of rest in bed about five weeks he was again allowed up and arrangements were made for electrocardiographic and X-ray examinations. Unfortunately these investigations were not carried out, as he developed a left-sided pleural effusion early in October. On October 18 he died suddenly in an acute heart attack.

Post-mortem Examination (Prof. J. McGrath).-The body was that of a wellbuilt man, of healthy appearance, with a moderate amount of fat. There was no evidence of bruising on the front of the chest. On opening the chest, the left pleural cavity was found to be almost completely filled with a large quantity of clear, straw-coloured fluid. The lower lobe of the left lung was entirely collapsed, as was also the lower portion of the upper lobe. The left lung itself, except for the above findings, appeared normal. There was the usual emphysema for a man of his age. The right lung showed old adherent pleurisy.

A moderate amount of fat surrounded the heart. The pericardium externally appeared thickened at the apex. On opening, it contained a small amount of fluid. At the apex over an area the size of a five-shilling piece there was fibrous adherent pericarditis. The heart muscle was thinned out under the area and formed a cardiac ventricular aneurysm. The heart was enlarged, especially the left ventricle, this enlargement being due to dilatation of the cavity with thinning of the muscle. The muscle (especially the apex) was permeated with fibrous tissue, and there was some endocarditis with adherent blood clot over an area the size of a half-crown. The aortic and mitral valves appeared 
efficient, but there was some simple atheroma. It did not seem possible that these valves could be the cause of the ventricular condition. There was no occlusion of the coronary arteries.

Examination of the ribs did not show any site of fracture in the bones. The

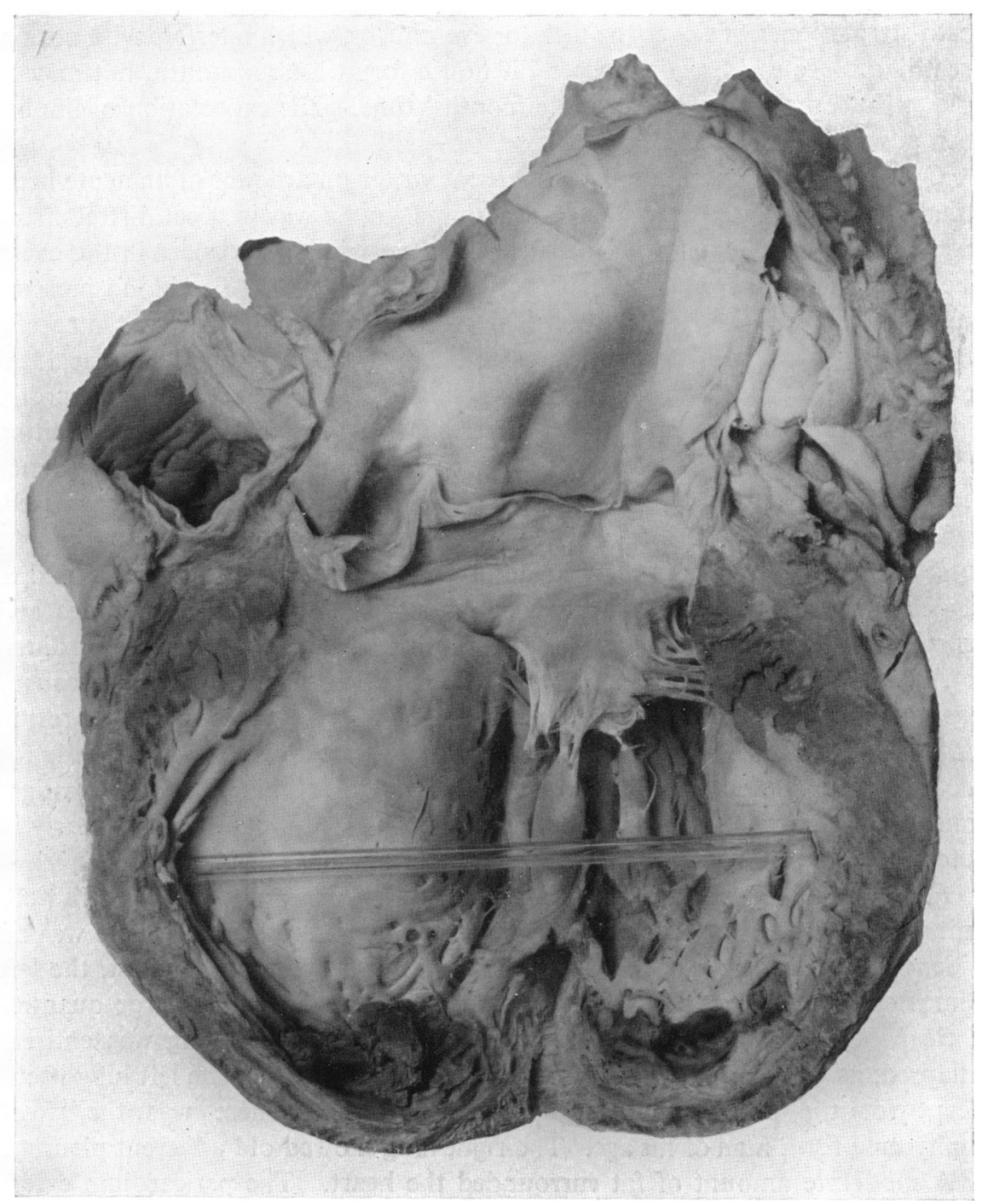

Figure illustrating traumatic aneurysm of the left ventricle, with apical myocardial fibrosis and localized endocardial thrombosis.

cartilaginous portion of the fifth, sixth, and seventh ribs over the heart apex was irregular and appeared to have been depressed slightly. There was a localized patch of pleurisy on the left parietal pleura posteriorly between the eleventh and twelfth ribs, in size about one and three-quarter inches in diameter. This patch of pleurisy was raised and reddish-yellow, and covered with granul- 
ation tissue ; it was evidently the cause of the pleural effusion, and was in direct line from back to front with the pericardial adhesion. A search was made for a rib fracture in the neighbourhood of this patch of pleurisy, but it could not be found.

Death was due to cardiac failure. This cardiac failure was caused by degeneration of the heart muscle with consequent dilatation (aneurysm) and endocarditis of the left ventricle. The degeneration seemed to have spread from the pericardial adhesions. These adhesions and the localized pleurisy at the back were in direct line with the abnormality of the costal cartilages in front, and could have been the result of an impact on the chest. From the history of the case, the injuries sustained in the motor car accident were the original cause of the sequence of events that led to his death. There was, however, old-standing pleurisy on the right side, and some of the heart disease possibly antedated the accident.

\section{COMMENTS}

(1) Clinical Aspects.-Although this patient was obviously suffering from a grave cardiac condition throughout his illness, the true nature of the lesion was not fully appreciated, nor was a sudden death anticipated. Taken generally, the clinical picture resembled that of coronary thrombosis, except that a subacute form of "status anginosus" seemed to have persisted intermittently for several weeks. The constant tenderness over the præcordial area appeared to indicate damage to the underlying cardiac musculature.

An interesting point in the clinical history was the delay in the onset of cardiac symptoms after the accident. It appears, however, that a latent period is not an unusual finding ; for instance, Elkin (1935) cites a case of cardiac contusion following a motor-car collision, where the patient walked for a distance of 50 yards from the scene of the accident before he experienced shortness of breath. Beck (1935) also states that symptoms of cardiac injury may be delayed for hours and sometimes for days. Presumably in the present case the patient's heart was actually contused at the time of the impact ; but symptoms did not become manifest until the area of contusion, owing to extravasation of blood in the muscle, simulated a myocardial infarct.

The occurrence of auricular fibrillation following direct trauma to the chest wall has been observed by Barber (1938), White (1937), the Khans (1928), and others, and therefore it cannot be regarded as an unusual complication. The development of " tic tac" heart sounds in cardiac trauma has been shown by Bright and Beck (1935) to occur experimentally in dogs, and the same writers have observed a similar phenomenon in human beings following non-penetrating injuries of the thorax. A very striking feature in the present case was the peculiar short "whiffing" type of breathing, which may perhaps have been of some diagnostic significance though at the time it was unaccounted for. The state of anxiety and nervousness shown by the patient was seldom absent and on several occasions amounted to a veritable " angor animi."

As no electrocardiogram or X-ray photograph was taken, one can only 
speculate on the possible findings. The post-mortem lesion suggests that during life an electrocardiographic tracing might have shown inversion of $\mathrm{T}$ in lead $\mathrm{I}$, indicative of damage to the anterior and apical portion of the left ventricle, which might have been misinterpreted as pointing to a true coronary thrombosis. On the criteria given by Parkinson, Bedford, and Thompson (1938) it is unlikely that an X-ray photograph would have disclosed the presence of an aneurysm, for the heart as it lay in situ did not show marked bulging of the ventricular wall.

(2) Medico-legal Aspects.-Fortunately for most of those concerned, the case was settled out of court with substantial monetary compensation to the dependants of the deceased. There is no doubt that had the case come to trial certain difficulties might have arisen. The history of an injury in a previously healthy man would of course have carried considerable weight in a court of law, but it would have been impossible, without the post-mortem findings, to state definitely that no coronary disease had existed previously. If some coronary disease had been disclosed at the post-mortem examination it would have been rather difficult to decide how far the injury had aggravated a preexisting disease so as to cause fatal outcome. Should the patient have survived, the question of assessing compensation might have proved even more difficult.

\section{REFERENCES}

Barber, H. (1938). Brit. med. J., 1, 433.

Beck, C. S. (1935). J. Amer. med. Ass., 104, 109.

Bright, E. F. and Beck, C. S. (1935). Amer. Heart J., 10, 393.

Elkin, D. C. (1935). J. Southern med. Ass., 28, 4.

Khan, M. N., and Khan, S. (1928). Ann. intern. Med., 2, 1013.

Parkinson, J., Bedford, D. E., and Thompson, W. A. R. (1938). Quart. J. Med., 7, 455.

Warburg, E. (1938). Subacute and Chronic Pericardial and Myocardial Lesions due to Nonpenetrating Traumatic Injuries. Oxford Univ. Press (English translation).

White, P. D. (1937). Heart Disease, New York. 